\title{
APLIKASI MEDIA INTERAKTIF MENGGUNAKAN ANIMASI CERITA RAKYAT UNTUK ANAK USIA DINI (Studi Kasus Yayasan Bina Insan Kamil Kabupaten Tangerang)
}

\author{
Arsi Yulianjani ${ }^{1}$ \\ Aris Martono ${ }^{2}$ \\ Dwika Apriyani ${ }^{3}$ \\ Dosen AMIK Raharja Informatika ${ }^{1}$, Dosen STMIK Raharja ${ }^{2}$, Mahasiswa STMIK Raharja ${ }^{3}$

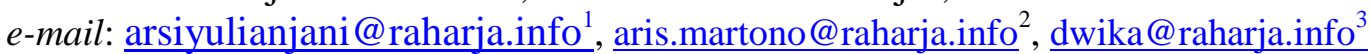

\begin{abstract}
ABSTRAKSI
Tujuan penelitian ini adalah merancang aplikasi media interaktif dengan menggunakan animasi cerita rakyat untuk anak usia dini. Media ini dibuat untuk membantu anak usia dini dalam belajar dan menarik minat belajar dengan menggunakan gambar/ animasi. Pengenalan cerita-cerita rakyat pada anak usia dini yang berusia 4- 5 tahun atau sekolah Taman Kanak-kanak (TK) sangat penting bagi pertumbuhan dan perkembangan anak karena cerita rakyat berisi pesan-pesan moral yang bernilai positif dapat membangun kecerdasan emosional anak serta perkembangan karakter dalam proses pembentukan watak anak. Metode perancangan yang digunakan untuk membuat media interaktif dengan animasi cerita rakyat adalah aplikasi program komputer video grafis, diantaranya: Adobe Flash Professional CS6, Adobe Audition CS6 dan CorelDRAW X7. Aplikasi ini diawali dengan tahap-tahap perancangan yaitu: Preproduction, Story board, Script writing, Post Production, Editing, Mixing dan Finishing. Hasil dari penelitian ini adalah sebuah aplikasi media interaktif menggunakan animasi cerita rakyat, yang berguna untuk pembelajaran anak usia dini.
\end{abstract}

Kata Kunci: Media interaktif, cerita rakyat, anak usia dini

\section{ABSTRACT}

The purpose of this study is to design interactive media applications using animated folklore for early childhood. This media is created to help early childhood in learning and attract interest in learning by using images / animation. The introduction of folk tales in children aged 4-5 years or kindergartens (TK) is very important for the growth and development of children because folklore contains positive moral messages that can build children's emotional intelligence and character development in the process of forming a child's character. Interactive media design methods with animated folklore are produced using the application of graphic video computer programs including: Adobe Flash Professional CS6, Adobe Audition CS6 and CorelDRAW X7. This application begins with the design stages, namely: Preproduction, Story board, Script writing, Post Production, Editing, Mixing and Finishing. The result of this study is an interactive media application using animated folklore, which is useful for early childhood learning.

Keywords: Interactive media, Folklore, Childhood

\section{PENDAHULUAN}

\section{Latar Belakang}

Perkembangan teknologi serta ilmu pengetahuan mengalami kemajuan yang begitu pesat. Saat ini ragam media pembelajaran semakin berkembang, seperti media pembelajaran berbasis visual, audio visual, komputer, Microsoft Power Point, internet, dan interactive video. 
Pikiran, perasaan, dan kemauan penonton-siswa--yang dapat diyakinkan dan dirangsang oleh sesuatu sehingga penonton tersebut mempunyai keinginan untuk belajar disebut media. Media ini dapat menjadi alat bantu yang digunakan sebagai penyampai pesan untuk mencapai tujuan pembelajaran. Media ini bagi anak usia dini harus mempunyai daya tarik yang besar agar anak termotivasi dalam pembelajaran.

Sekumpulan gambar yang disusun secara beraturan dan mengikuti alur pergerakan yang ditentukan dan berupa visual yang bergerak disebut animasi. Biasanya seorang animator menuangkan pemikiran dan idenya menggunakan animasi supaya tidak terlihat biasa.

Pendidikan yang diberikan bagi anak usia dini (0-6 tahun) yang dilakukan haruslah dapat memberikan rangsangan dalam membantu tumbuh kembang anak, secara jasmani maupun rohani supaya anak siap untuk memasuki jenjang pendidikan berikutnya.[1]

Pengamatan terhadap 85 siswa (usia 4-5 tahun) RA YABIKA, dimana penyampaian materi menggunakan media pembelajaran LKS (Lembar Kerja Siswa), cukup sulit dipahami oleh siswa dan secara visual kurang kreatif maka hal ini dapat mengurangi minat siswa dalam melakukan pembelajaran.

Pengenalan cerita-cerita rakyat bagi mereka sangat penting untuk pertumbuhan dan perkembangan mereka karena cerita rakyat berisi pesan-pesan moral yang bernilai positif dan membangun kecerdasan emosional serta perkembangan karakter dalam proses pembentukan watak.

Oleh karena itu penelitian ini untuk merancang aplikasi media interaktif animasi cerita rakyat untuk anak usia dini. Siswa diharapkan dapat mengenal karakter tokoh dan pesan-pesan moral yang ada dalam cerita, menumbuhkan rasa nasionalisme pada diri siswa, dan meningkatkan minat siswa dalam proses belajar. Dengan demikian penelitian ini dapat dirumuskan permasalahannya antara-lain:

1. Bagaimana strategi pembelajaran kreatif dalam proses pembelajaran?

2. Bagaimana peran video animasi cerita rakyat tehadap kegiatan pembelajaran?

3. Apa manfaat yang akan diperoleh melalui cerita rakyat dalam bentuk video animasi?

Agar pembahasan masalah dapat lebih terarah, ruang lingkup pembahasan dibatasi pada perancangan aplikasi media interaktif dengan menggunakan video animasi cerita rakyat.

\section{METODE PENELITIAN}

\section{Metode Pengumpulan Data}

1. Observasi

Melakukan observasi dengan melakukan pengamatan secara langsung di tempat penelitian yaitu di RA YABIKA, untuk mengumpulkan data proses penyusunan laporan penelitian.

2. Wawancara

Dengan melakukan wawancara atau tanya jawab dengan narasumber atau stakeholder yang terlibat langsung dalam materi pembahasan ini.

3. Studi Pustaka, yang diperoleh dari berbagai sumber seperti buku-buku, jurnal, dan media tertulis lain yang berhubungan dengan topik penelitian.

\section{Metode Analisa Perancangan Media}

Perancangan media interaktif animasi yang digunakan adalah aplikasi program komputer video grafis seperti Adobe Flash Professional CS6, Adobe Audition CS6 dan CorelDRAW X7.

Tahapan dalam perancangan media interaktif ini, terlihat pada gambar 1 di bawah ini: 


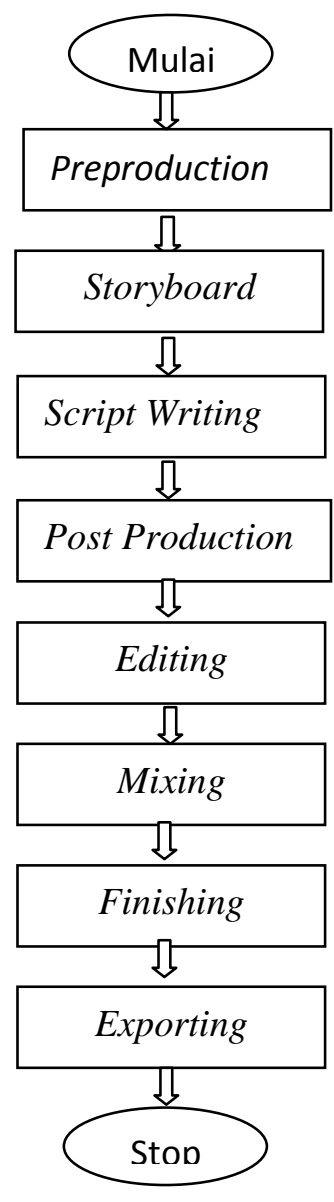

Gambar 1. Tahapan Perancangan Media Interaktif

\section{KAJIAN LITERATUR}

\section{Media}

Saluran penyampaian pesan komersial kepada audiens sasaran disebut media[2] Media adalah Sesuatu yang bersifat meyakinkan pesan dan dapat merangsang pikiran, perasaan, dan kemauan audiens atau siswa sehingga dapat mendorong terjadinya proses belajar pada diri siswa.[3] Saluran penyampaian pesan komersil yang digunakan kepada publik sasaran atau dapat dikatakan salah satu komunikasi periklanan dengan menggunakan saluran media tertentu, seperti televisi, surat kabar, majalah, radio, internet, buku profil, media luar ruangan, iklan transit dan direct mail..[4]

\section{Desain}

Sebuah perencanaan dalam pembuatan objek, system, komponen atau struktur dinamakan desain. Pengertian lainnya adalah seni terapan dan rekayasa yang berintegrasi dengan teknologi.[5] Penampilan visual secara menyeluruh dari iklan sebagai art direction atau desain. Melalui proses standar dengan membuat sketsa-sketsa kasar, menentukan alternatif desain, hingga final artwork (FAW) untuk memadukan antara art direction dan copywriter (berupa konsep verbal dan visual) secara sinergis ke dalam desain[6]

Beberapa unsur dasar dalam membuat sebuah desain mencakup[7]:

1. Garis (Line) adalah penghubung antara satu titik poin dengan titik poin yang lain.

2. Bentuk (Shape) adalah semua unsur yang memiliki diameter, tinggi, dan lebar. Bentuk-bentuk dasar yang yang dikenal umum seperti: bentuk kotak (rectangle), lingkaran (circle), segitiga (triangle), lonjong (elips), dan lain-lain.

3. Tekstur (Texture) adalah tampilan permukaan atau corak dari suatu benda yang dapat dinilai dengan cara dilihat atau diraba. 
4. Gelap Terang/Kontras merupakan warna yang berlawanan antara satu dengan lainnya, terdapat perbedaan baik warna atau titik fokus. Apabila tidak berwarna, dapat pula berupa perbedaan antara gelap dan terang.

5. Ukuran (Size) adalah perbedaan ukuran, besar kecilnya suatu obyek. Dengan adanya unsur ini, maka dapat menciptakan kontras dan penekanan (emphasis) pada objek desain yang hendak dibuat.

6. Warna (Color) adalah hal yang penting dalam objek desain. Dengan menggunakan warna dapat menampilkan identitas/citra yang ingin disampaikan.

Dalam mendesain obyek, ada beberapa prinsip kerja desain yang harus selalu diterapkan[15] yaitu:

1. Keseimbangan (Balance) merupakan pembagian berat yang sama, baik secara visual maupun optik. Desain dinyatakan seimbang apabila obyek pada bagian kiri atau kanan, bagian atas atau bawah terkesan sama berat.

2. Irama (Rhythm) diartikan sebagai pengulangan gerak atau penyusunan bentuk secara berulangulang. Dalam desain, irama dapat berupa repetisi atau variasi.

3. Penekanan/Dominasi (Emphasis), salah satu prinsip dasar tatarupa dan harus dipunyai dalam karya seni dan desain.

4. Kesatuan (Unity) adalah hal terpenting, karena tanpa adanya kesatuan dalam sebuah karya maka karya tersebut menjadi terlihat tercerai-berai, dan kacau-balau.

\section{Desain Grafis}

"Suatu bentuk komunikasi visual dan seni yang mampu menyampaikan informasi dan pesan yang efektif kepada penikmat ataupun konsumen disebut desain grafis."[7]

"Seni olah gambar, ilustrasi, foto, dan media lainnya untuk keperluan komunikasi visual dinamakan desain grafis.”[8]

\section{Tipografi}

Tipografi adalah ilmu yang mempelajari tentang tata letak sebuah huruf atau kalimat agar terlihat indah dan dapat dengan mudah menyampaikan pesan yang ingin disampaikan kepada pembacanya.[9] Tipografi juga diartikan sebagai ilmu yang mempelajari tentang penempatan, penataan huruf untuk mendapatkan kesan tertentu agar pembaca bisa mendapat informasi secara maksimal.[10]

\section{Layout}

Layout diartikan sebagai usaha untuk penyusunan, penataan atau pemaduan dari bagian-bagian komunikasi grafis seperti teks, gambar, table, dll sehingga media komunikasi visual menjadi komunikatif, estetik dan menarik.[10] Layout juga dapat berartikan penyusunan dari unsur-unsur desain yang saling berkaitan ke dalam sebuah bidang sehingga membentuk susunan artistic.[7]

\section{Jenis Layout}

Terdapat tahapan dalam membuat layout, tergantung pada jenis-jenis layout diantaranya adalah[11] :

1. Layout kasar, yaitu penerapan unsur-unsur desain media yang nantinya akan dipakai dalam pembuatan media yang disertai acuan standarisasi pada desain yang akan dibuat, biasanya dengan tampilan hitam putih, dan dengan coretan atau sketsa yang menggunakan pensil gambar.

2. Layout komprehensif, yaitu proses perancangan yang memasuki tahap komputerisasi dan pewarnaan, namun tahap ini belum selesai seluruhnya, karena masih harus mengalami proses revisi dinamakan.

3. Final Art Work, adalah hasil akhir dari layout komprehensif yang telah diperbaiki. Dalam tahap ini disebut hasil akhir atau finishing, kemudian dapat digunakan untuk acuan saat proses produksi.

\section{Media Interaktif}

Multimedia yang tidak bersifat linier, namun pengguna (user) memiliki pilihan sesuai dengan menu yang ditawarkan sebagai media interaktif.[12]

Suatu sistem gambar yang hidup atau dapat bergerak dan saling berurutan dinamakan video.[13] Video ini menggabungkan gambar-gambar mati yang dibaca berurutan dalam suatu waktu dengan 
kecepatan tertentu.[14] Video diartikan juga sebagai teknologi penangkapan, perekaman, pemrosesan, pentransmisian dan penataan ulang gambar bergerak.[15]

Sebelum melakukan ke tahap pengiriman, pengeditan, dan penyimpanan hasil rekaman, sebaiknya memahami terlebih dulu bermacam format video yang dapat digunakan[16] yaitu AVI( Audio Video Interlaced, MPEG-1(Motion Picture Expert Group 1),

MPEG-2(resolusi sampai 720 x 576 pixel), MPEG-4(resolusi 640 x 480 pixel), MOV(format standar Apple), MJPEG(Motion JPEG), ASF( Advanced Streaming Format), WMV(Windows Media Video) dan AAC (Advanced Audio Coding).

\section{Multimedia}

Multimedia merupakan perpaduan bentuk-bentuk unsur informasi seperti teks, grafik, gambar, foto, animasi, audio dan video, yang dipakai sebagai alat menyampaikan tujuan tertentu.[3]

Multimedia juga dapat diartikan penggunaan komputer dalam penyajian dan penggabungan teks, suara, gambar, animasi dan video yang menggunakan alat bantu (tool) dan koneksi (link) sehingga pengguna dapat melakukan navigasi, berinteraksi, berkarya dan berkomunikasi.[17]

\section{Audio Visual}

Proses penyampaian pesan atau informasi dari sumber kepada satu penerima atau lebih dengan cara memvisualisasikan dan memperdengarkan isi pesan atau informasi kepada penerima dengan melalui media dinamakan audio visual.[18]

Media audio visual dibagi dua[19], yaitu:

1. Audio Visual Diam(menampilkan suara dan gambar seperti bingkai suara /sound slide).

2. Audio Visual Gerak( menampilkan elemen suara dan gambar bergerak seperti film dan video).

\section{Sinopsis}

Sinopsis adalah ringkasan sebuah cerita yang diperlukan untuk memberikan gambaran secara ringkas dan padat tentang tema atau pokok cerita secara keseluruhan.[20] Sedangkan naskah adalah karangan yang masih ditulis dengan tangan.[21]

\section{Storyboard}

Storyboard adalah rancangan tampilan yang mendeskripsikan fungsi dari fitur-fitur yang disediakan pada suatu aplikasi yang dibuat secara rinci dan tepat.[22] Sedangkan alat atau sarana yang digunakan untuk menafsirkan deskripsi tertulis dari unsur gambar yang terdapat di dalam sebuah naskah dinamakan storyboard.[23]

\section{Animasi}

Suatu disiplin ilmu yang memadukan unsur seni dengan teknologi dinamakan animasi. Animasi ini sebagai cabang sinematografi karena animasi ini sendiri tidak terlepas dari disiplin ilmu film itu sendiri.[24]

"Animation is the process of recording and playing back a sequence of stills to achieve the illusion of continues motion." (Animasi adalah sebuah proses merekam dan memainkan kembali serangkaian gambar statis untuk mendapatkan sebuah ilusi pergerakan.”)[25]

\section{Cerita Rakyat}

Cerita rakyat adalah salah satu sumber utama untuk meneruskan sastra tradisional dari satu generasi ke generasi selanjutnya. Dengan cerita rakyat, imajinasi anak dapat dikembangkan sehingga mereka menjadi pribadi yang kreatif serta dapat menambah wawasan nilai sejarah dari cerita yang diwariskan dari generasi sebelumnya.[26] Cerita rakyat merupakan pencerminan dari kehidupan masyarakat pada saat itu, pola pikir dan hayalan yang menarik, sehingga masyarakat merasa tertarik dan memperoleh keteladanan.[27] Salah satu kebudayaan Indonesia yang mengandung nilai moral dan telah menjadi aturan-aturan tradisi masyarakat di suatu wilayah tertentu disebut juga cerita rakyat.[28] 


\section{Anak Usia Dini}

Anak usia dini merupakan anak yang berada pada rentang usia antara satu hingga lima tahun."[1] Gambaran manusia sebagai manusia disebut masa kanak-kanak[40]. Bahkan perilaku yang aneh pada masa dewasa dapat dideteksi melalui masa kanak-kanak. Secara umum masa kanak-kanak memiliki karakteristik atau sifat-sifat sebagai-berikut[29]:

1. Sifat anak tidaklah sama satu dengan yang lainnya(unik). Anak mempunyai bawaan, minat, kapabilitas, dan tradisi keluarga yang berbeda. Walaupun urutan pola perkembangan anak pada umumnya dapat diprediksi, namun pola dalam berkembang dan belajarnya tidaklah sama antara satu dengan yang lainnya.

2. Anak akan lebih melihat dan mempelajari sesuatu berdasarkan pemikiran dan kepentingannya sendiri (Egosentris).

3. Anak senang melakukan berbagai aktivitas(aktif dan energik).

4. Memiliki keingin tahuan yang besar dan antusias pada banyak hal.

5. Mengembangkan diri (Eksploratif) dan berjiwa petualang.

6. Spontanitas, perbuatan yang menampilkan sifat anak pada umumnya yang asli (natural) dan tidak dibuat-buat sehingga menampilkan apa yang ada dalam perasaan dan pikirannya.

7. Gembira dan banyak berhayal (fantasi).

8. Masih mudah frustasi.

9. Masih kurang dalam penalarannya.

10. Daya fokus yang tidak luas.

11. Semangat dalam belajar dan mencari jati diri.

12. Senang bersosialisasi dengan sebaya.

\section{Aplikasi Penunjang Video}

\section{Adobe Flash Professional CS6}

Sebuah software yang didesain khusus oleh Adobe dan program aplikasi standar authoring tool professional dan digunakan untuk pembuat animasi dan bitmap yang sangat menarik untuk keperluan pembangunan situs web yang interaktif dan dinamis adalah Adobe Flash CS6.[30]

Adobe Flash CS6 ini merupakan versi terbaru dari versi sebelumnya, Adobe Flash CS5.[31] Program ini memiliki banyak kegunaan dalam pembuatan animasi objek, presentasi, animasi iklan, game, pendukung animasi halaman web, sampai dengan pembuatan film animasi. Tampilan Jendela Adobe Flash Pro CS6 dapat dilihat pada gambar 2 di bawah ini.

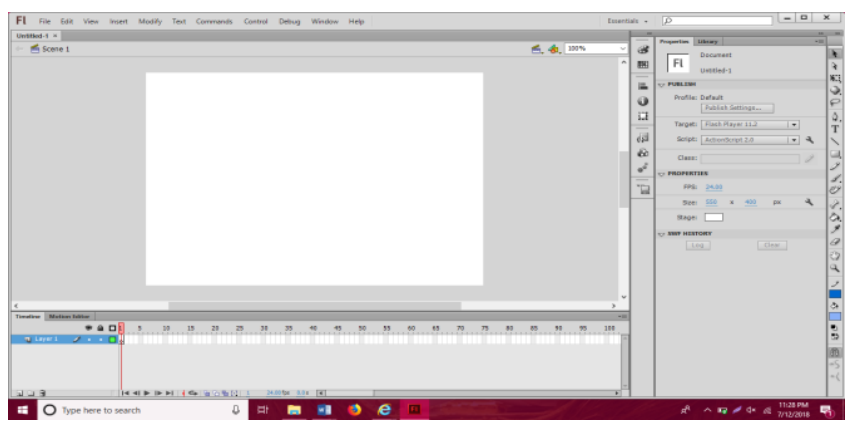

Gambar 2. Tampilan Jendela Adobe Flash Pro CS6

\section{Adobe Audition CS6}

Aplikasi multimedia untuk mengolah file audio. Adobe Audition adalah multitrack digital audio recording, editor, dan mixer yang mudah digunakan serta memiliki berbagai fasilitas, pengolahan audio disebut Adobe Audition.[32] Adobe Audition ini memiliki fasilitas perekam audio hingga 128 track hanya satu sound card. Pengeditan audio dapat dilakukan dalam bentuk .wav dan file outputnya dapat dikonversi dalam bentuk format audio, seperti .wma, .mp3, .mp3pro, dll.

Adobe Audition memberikan view yang berbeda untuk mengedit file audio. Jika ingin mengedit audio secara individual, maka dapat menggunakan Wavefrom Editor. Multitrack Editor digunakan untuk mengolah beberapa file audio dan mengintegrasikan dengan file audio. Wavefrom Editor dan 
Multitrack Editor menggunakan metode editing berbeda dan masing-masing memiliki kelebihan yang unik. Tampilan Jendela Adobe Audition CS6 dapat dilihat pada gambar 3 di bawah ini.

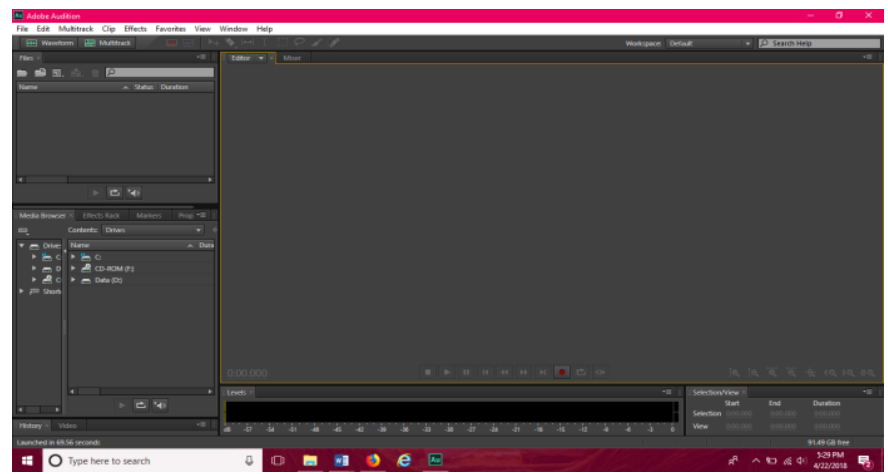

Gambar 3. Tampilan Jendela Adobe Audition CS6

\section{CorelDRAW}

Aplikasi grafis yang dengan format vector (koordinat), tidak seperti Macromedia Adobe Photoshop yang lebih mengutamakan format Bitmap (pixel) menggunakan CorelDraw.'[33] Tampilan Jendela CorelDRAW X7 ini dapat dilihat pada gambar 4 di bawah ini.

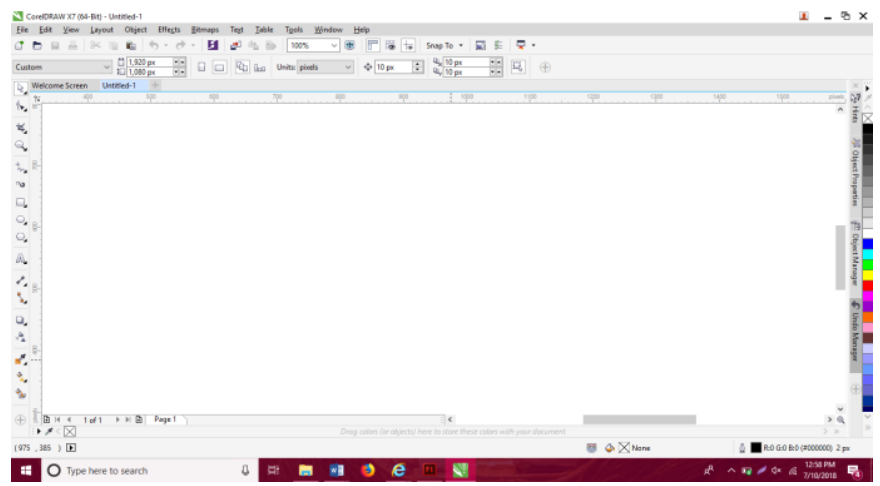

Gambar 4. Tampilan Jendela CorelDRAW X7

\section{LITERATURE REVIEW}

Berdasarkan literature review di bawah ini(lihat tabel 1 ), penelitian ini mengambil referensi pada literature review nomor 1 yang ditulis oleh Muhdaliha dan Batuaya (2017 : 61-72) ${ }^{[50]}$ dengan judul "Film Animasi 2 Dimensi Cerita Rakyat Bali Berjudul I Ceker Cipak". Dikarenakan tujuan penelitian yang digunakan sama yaitu untuk memperkenalkan cerita rakyat lokal, kepada anak-anak dan menanamkan nilai-nilai moral serta kesusilaan mulai sejak dini. Selain itu dapat menumbuhkan rasa cinta terhadap budaya daerah sendiri.

Tabel 1. Literature Review

\begin{tabular}{|c|c|c|c|}
\hline No. & $\begin{array}{c}\text { Penulis, } \\
\text { Judul Penelitian }\end{array}$ & Tujuan Penelitian & Metode Penelitian \\
\hline 1. & $\begin{array}{c}\text { Muhdaliha dan } \\
\text { Batuaya } \\
(2017: 61-72)^{[50]} \\
\text { "Film Animasi } 2 \\
\text { Dimensi Cerita } \\
\text { Rakyat Bali Berjudul } \\
\text { I Ceker Cipak" }\end{array}$ & $\begin{array}{c}\text { Tujuan penelitian ini } \\
\text { untuk memperkenalkan } \\
\text { cerita rakyat khusunya } \\
\text { cerita rakyat Bali, kepada } \\
\text { anak-anak dan } \\
\text { menanamkan nilai-nilai } \\
\text { moral serta kesusilaan } \\
\text { mulai sejak dini. Selain } \\
\text { itu dapat menumbuhkan }\end{array}$ & $\begin{array}{l}\text { Penelitian ini membagi } \\
\text { data penelitian menjadi } \\
\text { dua kategori yaitu data } \\
\text { primer dan data sekunder. }\end{array}$ \\
\hline
\end{tabular}




\begin{tabular}{|c|c|c|c|}
\hline & & $\begin{array}{c}\text { rasa cinta terhadap } \\
\text { budaya daerah sendiri. }\end{array}$ & \\
\hline 2. & $\begin{array}{l}\text { Jostonchoniv dan } \\
\text { Windarto (2013: 172- } \\
\text { 179) }{ }^{[51]} \text { "Pembuatan } \\
\text { Film Animasi 3D } \\
\text { Cerita Rakyat "The } \\
\text { Legend of Toba Lake" }\end{array}$ & $\begin{array}{c}\text { Tujuan penelitian ini } \\
\text { untuk dijadikan media } \\
\text { hiburan film animasi 3D } \\
\text { yang mengangkat cerita } \\
\text { rakyat Indonesia dan ikut } \\
\text { melestarikan keberadaan } \\
\text { cerita rakyat sebagai aset } \\
\text { budaya bangsa. }\end{array}$ & $\begin{array}{l}\text { Pembuatan film dengan } \\
\text { menggunakan metode } \\
\text { reviewer, melihat kembali } \\
\text { penelitian sebelumnya } \\
\text { yang bersangkutan } \\
\text { dengan cerita rakyat. }\end{array}$ \\
\hline 3. & $\begin{array}{c}\text { Kusmayadi, dkk }(2017 \\
\text { : } 902-909)^{[53]} \\
\text { "Pengembangan } \\
\text { Multimedia Cerita } \\
\text { Rakyat sebagai } \\
\text { Penumbuhan } \\
\text { Karakter Siswa" }\end{array}$ & $\begin{array}{l}\text { Penelitian ini bertujuan } \\
\text { untuk menguji kelayakan } \\
\text { multimedia apresiasi } \\
\text { cerita rakyat bermuatan } \\
\text { Pendidikan karakter untuk } \\
\text { siswa SMP kelas VII. }\end{array}$ & $\begin{array}{l}\text { Metode penelitian yang } \\
\text { dipilih untuk penelitian } \\
\text { ini adalah model } \\
\text { pengembangan R\&D } \\
\text { Cycle Borg \& Gall. }\end{array}$ \\
\hline 4. & $\begin{array}{c}\text { Purwanto dan Sutanto } \\
(2017: 43-48)^{[54]} \\
\text { "Pembuatan Media } \\
\text { Presentasi Animasi } \\
\text { Cerita Rakyat untuk } \\
\text { Anak Usia Dini } \\
\text { dengan Konsep } \\
\text { Pemilihan Alternatif } \\
\text { Alur Cerita" }\end{array}$ & $\begin{array}{c}\text { Tujuan penelitian ini } \\
\text { untuk membantu guru } \\
\text { dalam proses } \\
\text { pembelajaran dengan } \\
\text { menggunakan aplikasi } \\
\text { interaktif ini dan anak } \\
\text { dapat memahami isi cerita } \\
\text { dengan baik. }\end{array}$ & $\begin{array}{c}\text { Penelitian ini } \\
\text { menggunakan metode } \\
\text { pengumpulan data, } \\
\text { Analisa kebutuhan, } \\
\text { tahapan desain, produksi } \\
\text { gambar, pembuatan } \\
\text { animasi, pembuatan } \\
\text { interaktif, testing system, } \\
\text { penggunaan dan } \\
\text { pemeliharaan sistem dan } \\
\text { tahap evaluasi. }\end{array}$ \\
\hline 5. & $\begin{array}{c}\text { Ibrahim, et al } \\
(2015)^{[56]} \\
\text { "Multimedia Mobile } \\
\text { Learning Application } \\
\text { for Children's } \\
\text { Education: The } \\
\text { Development of } \\
\text { Mfolktales" }\end{array}$ & $\begin{array}{l}\text { Untuk merancang dan } \\
\text { mengembangkan aplikasi } \\
\text { multimedia cerita rakyat } \\
\text { Melayu (Mfolktales) } \\
\text { berdasarkan cerita rakyat } \\
\text { Melayu lokal untuk } \\
\text { pendidikan anak-anak. }\end{array}$ & $\begin{array}{c}\text { Penelitian ini } \\
\text { menggunakan lima fase } \\
\text { yang terlibat dalam siklus } \\
\text { hidup pengembangan: } \\
\text { analisis, pengembangan, } \\
\text { implementasi dan } \\
\text { evaluasi. }\end{array}$ \\
\hline
\end{tabular}

Penelitian ini menyajikan media interaktif animasi cerita rakyat yang dapat menarik perhatian siswa RA (Raudatul Athfal) YABIKA agar dapat memahami nilai-nilai moral yang ada pada media interaktif animasi cerita rakyat tersebut. Menampilkan karakter yang mudah diingat oleh siswa dengan tampilan yang sesuai dengan umur siswa.

\section{HASIL DAN PEMBAHASAN}

\section{Preproduction}

Pra produksi merupakan proses persiapan atau perencanaan untuk mempersiapkan kebutuhan dalam proses produksi mulai dari observasi dengan mengumpulkan data-data yang diperlukan, pengumpulan ide atau gagasan yang dilandaskan pada sasaran audience, menentukan tema, lalu dikembangkan menjadi sinopsis, kemudian sinopsis dikembangkan menjadi storyboard, hingga ke tahap pembuatan animasi.

\section{Sinopsis}

Sinopsis Animasi Cerita Rakyat Legenda Batu Kuwung seperti berikut: 
Pada masa pemerintahan Sultan Haji (tahun 1683-1678 M), hiduplah seorang saudagar kaya raya yang tinggal di sebuah desa di daerah Banten. Dengan kekuasaan dan kekayaannya, ia menjadi sombong dan bertindak sewenang-wenang terhadap warganya.

Pada suatu hari, datanglah orang sakti yang menyamar sebagai seorang pengemis dengan kaki pincang untuk memberi pelajaran dan menyadarkan sang saudagar. Keesokan harinya, saudagar mendapati bahwa kakinya tidak dapat bergerak. Si pengemis berkaki pincang datang menemui sang saudagar dan mengatakan jika saudagar ingin sembuh, maka Ia harus pergi ke kaki Gunung Karang. Sang saudagar pun pergi ke kaki Gunung Karang dan memulai pertapaannya. Sikapnya pun berubah menjadi dermawan dan bijaksana dalam melaksanakan tugasnya menjadi kepala desa sehingga para warga menyukainya.

\section{Storyboard}

Storyboard adalah sketsa gambar untuk menggambarkan sekaligus menyampaikan suatu ide cerita kepada orang lain agar lebih mengerti atau memiliki khayalan yang sesuai dengan hasil karya yang akan dihasilkan. Sketsa gambar disusun sesuai dengan naskah yang telah dirancang seperti gambargambar (lihat gambar 5, 6 dan 7) di bawah ini.

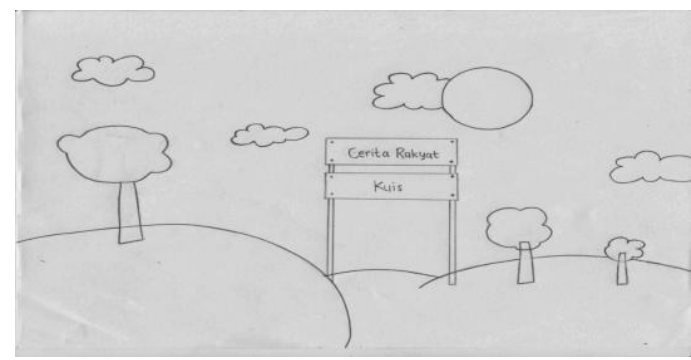

Gambar 5. Sketsa tampilan depan

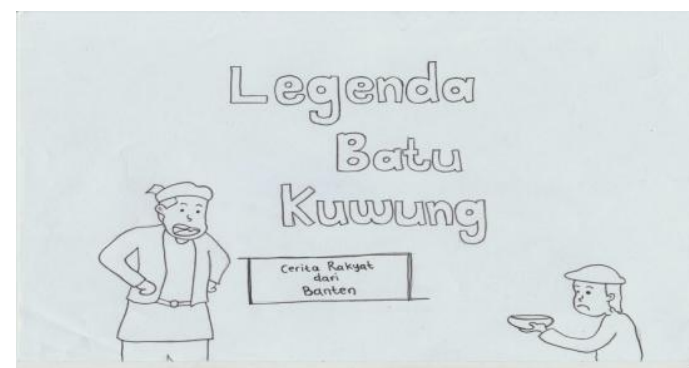

Gambar 6. Sketsa Tampilan Judul cerita rakyat

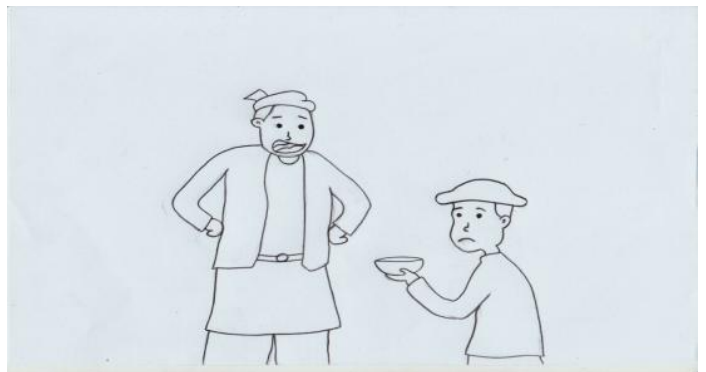

Gambar 7. Sketsa Tampilan Scene 8

\section{Script Writing}

Script Writing atau yang biasa disebut naskah adalah sebuah ide dasar atau gagasan cerita yang ditulis dengan sebuah konsep menarik untuk menampilkan suatu gagasan yang telah didesain sebelumnya. Script Writing aplikasi media interaktif ini dpat dilihat pada tabel 1 di bawah ini. 
Tabel 1. Script Writing

\begin{tabular}{|c|c|c|}
\hline No. & Visual & Audio \\
\hline 1. & $\begin{array}{l}\text { Menampilkan halaman depan berupa } 2 \text { pilihan } \\
\text { menu yaitu cerita rakyat dan kuis }\end{array}$ & Instrument.mp 3 \\
\hline 2. & Menu 1 menampilkan cerita rakyat & Instrument .mp3 \\
\hline 3. & $\begin{array}{l}\text { Menampilkan judul cerita rakyat "Legenda } \\
\text { Batu Kuwung, cerita rakyat daerah Banten" }\end{array}$ & Instrument .mp3 \\
\hline 4. & $\begin{array}{l}\text { Menampilkan adegan kamera masuk dari atas } \\
\text { awan, out frame zoom suasana rumah seorang } \\
\text { saudagar kaya raya }\end{array}$ & $\begin{array}{c}\text { Relaxing Music - } \\
\text { Tradisional Music West } \\
\text { Java.mp3 } \\
\text { Di sebuah desa, di daerah } \\
\text { Banten, hiduplah seorang } \\
\text { saudagar yang kaya raya. } \\
\text { Sayangnya, ia memiliki sifat } \\
\text { yang sombong dan kikir. }\end{array}$ \\
\hline 5. & $\begin{array}{l}\text { Menampilkan saudagar kaya yang sedang } \\
\text { berada di depan rumahnya }\end{array}$ & $\begin{array}{c}\text { Relaxing Music - } \\
\text { Tradisional Music West } \\
\text { Java.mp3 } \\
\end{array}$ \\
\hline 6. & $\begin{array}{l}\text { Menampilkan warga yang sedang } \\
\text { berkomunikasi membicarakan saudagar kaya }\end{array}$ & $\begin{array}{l}\text { Waah, rumahnya besar ya. } \\
\text { Sayang pelit. Padahal } \\
\text { hartanya melimpah. }\end{array}$ \\
\hline 7. & $\begin{array}{l}\text { Menampilkan kedatangan orang sakti yang } \\
\text { menyamar sebagai seorang pengemis dengan } \\
\text { kaki pincang ke rumah saudagar kaya }\end{array}$ & $\begin{array}{c}\text { Lalu datanglah orang sakti } \\
\text { yang menyamar sebagai } \\
\text { pengemis berkaki pincang } \\
\text { ke rumah saudagar kaya } \\
\text { raya. }\end{array}$ \\
\hline 8. & $\begin{array}{l}\text { Menampilkan saudagar kaya yang sedang } \\
\text { mengusir pengemis }\end{array}$ & $\begin{array}{c}\text { "Permisi, Nak. Saya lapar. } \\
\text { Bolehkah saya meminta } \\
\text { makanan?" } \\
\text { "Hey, Pak! Bekerjalah agar } \\
\text { mendapatkan uang dan } \\
\text { makanan! Jangan hanya } \\
\text { meminta-minta!" }\end{array}$ \\
\hline 9. & Menampilkan saudagar masuk rumah & $\begin{array}{c}\text { Mendapat perlakuan seperti } \\
\text { itu, pengemis } \\
\text { memperingatkan bahwa sang } \\
\text { saudagar akan mendapatkan } \\
\text { balasan yang setimpal atas } \\
\text { perbuatannya. }\end{array}$ \\
\hline 10. & Menampilkan timelapse sunrise & $\begin{array}{l}\text { Keesokan harinya, saudagar } \\
\text { mendapati bahwa kakinya } \\
\text { tidak dapat bergerak. Ia } \\
\text { memerintahkan pengawal } \\
\text { pribadinya untuk mencari } \\
\text { tabib-tabib sakti untuk } \\
\text { mengobati kakinya yang }\end{array}$ \\
\hline
\end{tabular}




\begin{tabular}{|c|c|c|}
\hline & & $\begin{array}{c}\text { lumpuh. Ia menjanjikan } \\
\text { imbalan yang sangat tinggi } \\
\text { bagi siapa saja yang dapat } \\
\text { menyembuhkannnya. }\end{array}$ \\
\hline 11. & Menampilkan saudagar bangun tidur & $\begin{array}{c}\text { "Eeh, kenapa kakiku rasanya } \\
\text { aneh, tidak bisa digerakkan? } \\
\text { Toloooong, kakiku lumpuh! } \\
\text { Cepat carikan tabib sakti } \\
\text { yang bisa menyembuhkan } \\
\text { kakiku! Akan aku berikan } \\
\text { imbalan yang sangat tinggi } \\
\text { bagi siapa saja yang dapat } \\
\text { menyembuhkannnya." }\end{array}$ \\
\hline 12. & Menampilkan suasana desa & $\begin{array}{c}\text { Relaxing Music - } \\
\text { Tradisional Music West } \\
\text { Java.mp3 }\end{array}$ \\
\hline 13. & $\begin{array}{l}\text { Menampilkan pengemis pincang datang ke } \\
\text { rumah saudagar kaya }\end{array}$ & $\begin{array}{c}\text { Mendengar janji tersebut, } \\
\text { pengemis berkaki pincang } \\
\text { datang menemui sang } \\
\text { saudagar. } \\
\text { “ Hey, Nak. Musibah yang } \\
\text { menimpa kedua kakimu } \\
\text { adalah akibat dari sifatmu } \\
\text { yang sombong dan kikir. } \\
\text { Jika kau ingin sembuh, maka } \\
\text { kau harus mau } \\
\text { melaksanakan } 3 \text { syarat, yaitu } \\
\text { kau harus mengubah sifat } \\
\text { sombong dan kikirmu, } \\
\text { pergilah ke kaki Gunung } \\
\text { Karang untuk bertapa di } \\
\text { sebuah batu cekung selama } 7 \\
\text { hari } 7 \text { malam tanpa makan } \\
\text { dan minum, dan berikan } \\
\text { setengah hartamu kepada } \\
\text { orang miskin setelah kau } \\
\text { sembuh.” }\end{array}$ \\
\hline 14. & Menampilkan pemandangan Gunung Karang & $\begin{array}{c}\text { Sang Saudagar pun mau } \\
\text { melakukan syarat-syarat } \\
\text { tersebut. Dia pergi ke kaki } \\
\text { Gunung Karang dengan } \\
\text { ditandu pengawalnya. }\end{array}$ \\
\hline 15. & $\begin{array}{l}\text { Menampilkan saudagar tiba di kaki gunung } \\
\text { Gunung Karang }\end{array}$ & $\begin{array}{c}\text { Setelah mencapai kaki } \\
\text { Gunung Karang dan menaiki } \\
\text { batu cekung, sang Saudagar } \\
\text { langsung memulai } \\
\text { pertapaannya. }\end{array}$ \\
\hline 16. & $\begin{array}{l}\text { Menampilkan saudagar bertapa di sebuah batu } \\
\text { cekung }\end{array}$ & $\begin{array}{l}\text { Relaxing Music - } \\
\text { Tradisional Music West } \\
\text { Java.mp3 }\end{array}$ \\
\hline 17. & $\begin{array}{l}\text { Menampilkan batu cekung yang } \\
\text { menyemburkan mata air panas }\end{array}$ & $\begin{array}{l}\text { Setelah saudagar bertapa } \\
\text { selama } 7 \text { hari } 7 \text { malam dan } \\
\text { menahan rasa lapar dan } \\
\text { hausnya, tiba-tiba }\end{array}$ \\
\hline
\end{tabular}




\begin{tabular}{|c|c|c|}
\hline & & $\begin{array}{c}\text { menyembur sumber air } \\
\text { panas dari celah batu. } \\
\text { Kemudian mengenai kaki } \\
\text { sang saudagar kaya. } \\
\text { "Hah? Ada air panas yang } \\
\text { menyembur dari celah } \\
\text { batu!” } \\
\text { Lalu kaki sang saudagar pun } \\
\text { bisa digerakkan kembali. }\end{array}$ \\
\hline 18. & $\begin{array}{l}\text { Menampilkan suasana rumah sang saudagar } \\
\text { kaya }\end{array}$ & $\begin{array}{c}\text { Setelah kedua kakinya } \\
\text { sembuh, sang saudagar } \\
\text { kembali ke rumah. Ia segera } \\
\text { memenuhi janjinya } \\
\text { memberikan setengah dari } \\
\text { hartanya kepada orang } \\
\text { miskin. Ia juga membagikan } \\
\text { lahan pertaniannya untuk } \\
\text { digarap oleh para petani } \\
\text { miskin. }\end{array}$ \\
\hline 19. & Menampilkan suasana desa & $\begin{array}{c}\text { Sikapnya pun berubah } \\
\text { menjadi dermawan dan } \\
\text { bijaksana dalam } \\
\text { melaksanakan tugasnya } \\
\text { menjadi kepala desa } \\
\text { sehingga para warga } \\
\text { menyukainya. }\end{array}$ \\
\hline 20. & Menampilkan pesan moral dari cerita tersebut & Instrument.mp3 \\
\hline 21. & Menampilkan logo STMIK Raharja & Instrument.mp3 \\
\hline 22. & Menu 2 menampilkan kuis & $\begin{array}{l}\text { Moana - How Far I'll Go } \\
\text { (Acoustic Version).mp3 }\end{array}$ \\
\hline
\end{tabular}

\section{Post Production}

Tahap selanjutnya adalah tahap post production, yaitu tahap editing, mixing finishing, tahap keluaran dan segmen pasar.

\section{Editing}

Pada tahap editing, pembuatan media interaktif dengan animasi cerita rakyat ini hanya menggunakan software bantu seperti CorelDRAW dan Adobe Flash. Kedua software ini sangat berperan penting dalam pembuatan media interaktif. Dalam pembuatan animasi ini menggunakan teknik Frame to Frame. Banyaknya frame tergantung seberapa halus pergerakan pada animasi. Semakin banyak frame, maka akan semakin terlihat real (lihat gambar 8).

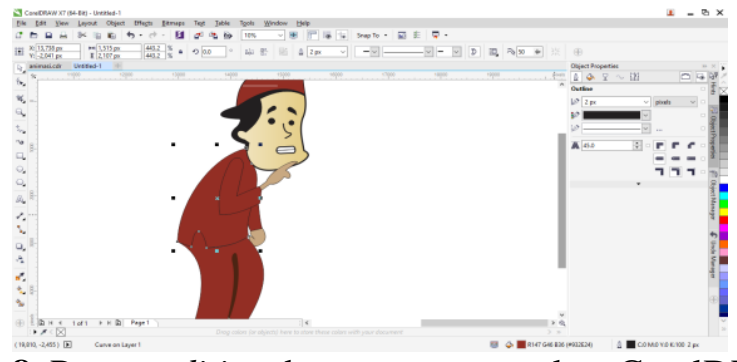

Gambar 8. Proses editing dengan menggunakan CorelDRAW X7 


\section{Mixing}

Tahap mixing adalah tahap penggabungan audio dengan video. Audio berupa musik instrument dan dubbing dimasukkan ke dalam media interaktif yang berupa animasi cerita rakyat (lihat gambar 9).

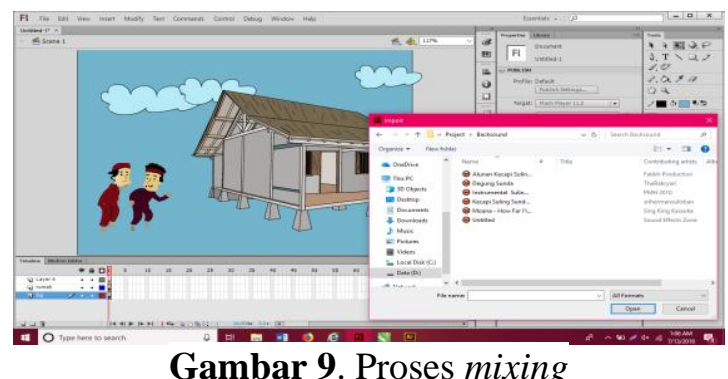

\section{Finishing}

Setelah proses editing dan audio mixing telah selesai dilakukan, maka tahap selanjutnya adalah tahap finishing, yaitu tahap penyelesaian dalam pembuatan media interaktif. Hasil scene-scene dan beberapa sound effect digabungkan sehingga menjadi satu kesatuan video yang utuh (lihat gambar 10).

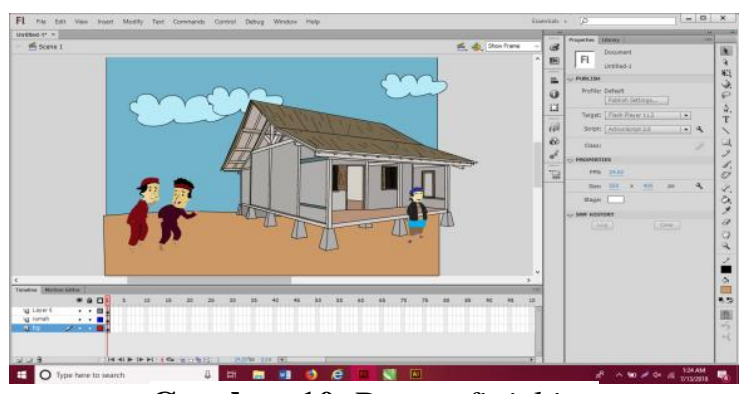

Gambar 10. Proses finishing

\section{Exporting}

Tahap exporting adalah tahap akhir dalam perancangan media interaktif. Selanjutnya hasil media interaktif di export dan disimpan (lihat gambar 11).

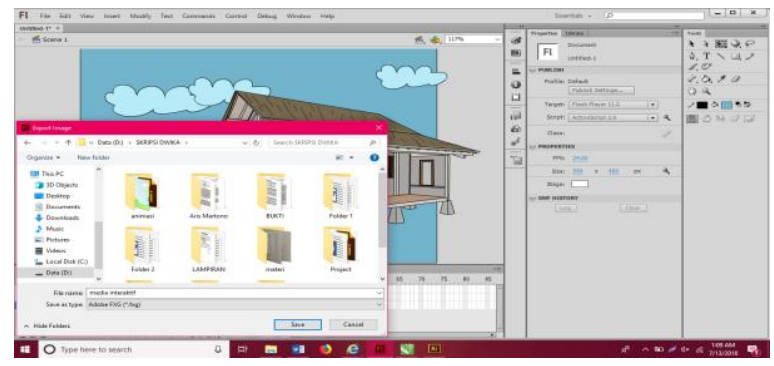

Gambar 11. Proses exporting

\section{KESIMPULAN}

Setelah membahas penelitian ini seperti diuraikan di atas, maka hal ini dapat disimpulkan mengenai perancangan aplikasi media interaktif dengan animasi cerita rakyat seperti-berikut:

1. Media yang dibutuhkan RA YABIKA untuk menyampaikan pembelajaran melalui media interaktif dengan animasi cerita rakyat, dikarenakan media tersebut dapat menjadi alternatif guru dalam menyampaikan pembelajaran yang lebih kreatif, inovatif, dan menyenangkan.

2. Media interaktif dengan animasi cerita rakyat ini dapat meningkatkan minat anak untuk memperhatikan pembelajaran, selain itu media interaktif animasi cerita rakyat ini juga dapat mengenalkan cerita rakyat daerah sehingga meningkatkan rasa nasionalisme pada anak usia dini. 
3. Manfaat yang didapatkan dengan adanya aplikasi media interaktif animasi cerita rakyat ini dapat membantu anak memahami nilai-nilai moral yang disampaikan dalam cerita ini sehingga meningkatkan kecerdasan emosional anak.

\section{DAFTAR PUSTAKA}

[1] Susanto, Ahmad. 2017. Pendidikan Anak Usia Dini (Konsep dan Teori). hal 1, 16.Jakarta: PT. Bumi Aksara

[2] Tjiptono, Fandy. 2015. Strategi Pemasaran. Yogyakarta: ANDI

[3] Wati, Ega Rima. 2016. Ragam Media Pembelajaran. Jakarta: Kata Pena

[4] Wahyuni, Sri, Afina Miftahurrachmah, dan Ellen Nindya Purwa. 2017. Media Company Profile sebagai Penunjang Informasi dalam Meningkatkan Efektifitas Program Pemasaran pada Hotel Narita Tangerang. SEMNASTEKNOMEDIA Online Vol.5 No.1. Diambil dari: http://ojs.amikom.ac.id/index.php/semnasteknomedia/article/view/1639 (26 Maret 2018)

[5] Akbar, Muhammad Rio. 2016. Perancangan Logo Koperasi Alumni SMA 2 Padang Ar'Rozak (KOPASMANDA Ar'Rozak). hal 2. Open Journal System Vol.23 No.2. Diambil dari: http://lppm.upiyptk.ac.id/majalahilmiah/index.php/majalahilmiah/article/view/46 (10 April 2018)

[6] Sunarya, Lusyani, Ogi Dermawan, Muhammad Hanif Amrullah. 2016. Desain Media Sign System dan Himbauan sebagai Penunjang Informasi pada Yayasan Perguruan Islam Attaqwa. Hal 60. Tangerang: Journal SENSI Vol.2 No.1

[7] Anggraini S., Lia dan Kirana Nathalia. 2016. Desain Komunikasi Visual; Dasardasar Panduan untuk Pemula. Bandung: Nuansa Cendekia

[8] Enterprise, Jubilee. 2016. Kitab Desain Grafis Komplet untuk Pemula. Jakarta: Elex Media Komputindo

[9] Ahmad, Razan Fakhdary. 2017. Perancangan Promosi Topeng Benjang untuk Remaja Kota Bandung. E-Proceeding of Art \& Design Vol.4 No.1. Diambil dari:

http://libraryeproceeding.telkomuniversity.ac.id/index.php/artdesign/article/view/ 3087 (26 Maret 2018)

[10] Hendratman, Hendi. 2017. Computer Graphic Design. Bandung: Informatika Bandung

[11] Desrianti, Dewi Immaniar, Anita B. Wandanaya dan Asih Sumaryani. 2014. Perancangan Media Katalog sebagai Penunjang Informasi dan Promosi pada CV. Zero Store. Tangerang: CCIT Journal Vol.7 No.2 
[12] Kurniawan, Angga dan Yudha Anggana Agung. 2016. Pengembangan Media Pembelajaran Interaktif Menggunakan Lectora Inspire pada Mata Pelajaran Teknik Elektronika Ddasar untuk SMKN 2 Surabaya. Jurnal Pendidikan Teknik Elektro Vol.5 No.3. Diambil dari: http://jurnalmahasiswa.unesa.ac.id/index.php/jurnal-pendidikan-teknikelektro/article/view/16817 (10 April 2018)

[13] Sutrisno dan Aziz Ahmadi. 2014. Pembuatan Video Profil Sekolah Dasar Negeri Menadi Kabupaten Pacitan Berbasis Multimedia. Jornal Speed Vol.6 No.2. Diambil dari: http://www.ijns.org/journal/index.php/speed/article/view/1072 (10 April 2018)

[14] Ningsih, Listina Nadhia, Ray Tri Nugroho, I Nyoman Lingga Anjana. 2017. Produksi Program Musik Chamber dalam Bentuk Video Dokumenter pada PT. Mata Air Inspirasi (Swarna FMTV). Tangerang: ICIT Journal Vol.3 No.1

[15] Lasaufa, Elsa, Muhamad Fariz Firmansyah dan Setiawan Dandi. 2017. Video Alat Bantu Cek Proses Produksi di PT. Roda Prima Lancar. Tangerang: ICIT Journal Vol. 3 No.1

[16] Nugroho, Sarwo. 2014. Teknik Dasar Videografi. Yogyakarta: ANDI

[17] Arriesanti, Hani dewi, Muhamad Yusup dan Ceria Marcelina. 2014. Penerapan Multimedia Audio Galery Ilearning Community and Services (MAGICS) sebagai Media Penyimpanan Dokumentasi pada Perguruan Tinggi Raharja. Tangerang: CCIT Journal Vol.7 No.2

[18] Wandara, Rindu, Syafwandi dan Eliya Pebriyeni. 2017. Perancangan Promosi Pesona Alam Bukit Langkisau West Sumatera Melalui Audio Visual. Jurnal dekave Vol.5 No.2. Diambil dari: http://ejournal.unp.ac.id/index.php/dkv/article/view/8368 (11 April 2018)

[19] Purwono, Joni, Sri Yutmini dan Sri Anitah. 2014. Penggunaan Media Audio-Visual pada Mata Pelajaran Ilmu Pengetahuan Alam di Sekolah Menengah Pertama Negeri 1 Pacitan. Jurnal Teknologi Pendidikan dan Pembelajaran Vol.2 No.2. Diambil dari: http://jurnal.fkip.uns.ac.id/index.php/tp/article/view/3659/0 (11 April 2018)

[20] Fatoni, Ahmad dan Nofi Puspitasari. 2016. Perancangan Simulasi Pengembangan Sistem Programming Penyaluran Dana Zakat di Badan Amil Zakat Kota Serang Berbasis Multimedia. PROSISKO Vol.3 No.2. Diambil dari: http://ejurnal.lppmunsera.org/index.php/PROSISKO/article/view/32 (26 Maret 2018)

[21] Kurniawati, Teti. 2017. Naskah Khutbah Karya Uci Sanusi; Sebuah Edisi Teks dan Kajian Topik. JALADRI Vol.3 No.1. Diambil dari: http://jurnal.upmk.ac.id/index.php/jaladri/article/view/62 (26 Maret 2018) 
[22] Munir, Muhammad. 2014. Pengembangan Media Pembelajaran Interaktif Kompetensi Dasar Register Berbasis Inkuiri Terbimbing. Jurnal Pendidikan Teknologi dan Kejuruan Vol.22 No.2. Diambil dari: https://journal.uny.ac.id/index.php/jptk/article/view/8926 (26 Maret 2018)

[23] Pribadi, Benny A. 2017. Media dan Teknologi dalam Pembelajaran. Jakarta: KENCANA

[24] Soenyoto, Partono. 2017. Animasi 2D. Jakarta: Elex Media Komputindo

[25] Bentelu, Alan Stevenres, Steven Sentinuwo dan Oktavian Lantang. 2016. Animasi 3 Dimensi Pencegahan Cyber Crime (Studi Kasus: Kota Manado). E-journal Teknik Informatika Vol.8 No.1. Diambil dari: April 2018)

[26] Ismail, Muhammad. 2017. Aplikasi Komik Interaktif Cerita Rakyat Jambi Berbasis Android. Processor Vol.12 No.2. Diambil dari: http://ejournal.stikomdb.ac.id/index.php/processor/article/view/318 (5 April 2018)

[27] Ali, Hasbi. 2017. Transformasi Nilai Nilai Kearifan Lokal (Local Genius) dalam Proses Pembelajaran sebagai Upaya Pembentukan Karakter Bangsa pada SMA Se-Kabupaten Simeulue. http://www.jurnal.fkip.uns.ac.id/index.php/progresif/article/view/11091 (13 Juni 2018)

[28] Septarina, Aprilia Kartini dan Hadi. 2016. Perancangan Board Game Edukasi Pendidikan Moral dengan Menggunakan Tokoh Cerita Rakyat Nusantara Untuk Usia 13-15 Tahun. https://journal.ubm.ac.id/index.php/ruparupa/article/view/209 (13 Juni 2018)

[29] Yusuf, Syamsu dan Nani M. Sugandhi. 2016. Perkembangan Peserta Didik. Hal 4750. Jakarta: PT. RajaGrafindo Persada

[30] Hompu, Ummi Hidayah La, Muh. Yamin dan La Ode Hasnuddin S. Sagala. Multimedia Pembelajaran Interaktif Makhraj Huruf Hijaiyah, Wudu dan Salat Menggunakan Adobe Flash CS6 Berbasis Android. semanTIK Vol.2 No.2.Hal 103.

Diambil dari: http://ojs.uho.ac.id/index.php/semantik/article/view/1657 (12 April 2018)

[31] Fajarianto, Otto dan Radeal Wirawa. Aplikasi Alat Bantu Mengajar Matematika Menggunakan Adobe Flash CS6. Jurnal Sisfotek Global Vol.3 No.1. Hal 15. Diambil dari: https://stmikglobal.ac.id/journal/index.php/sisfotek/article/view/18 (18 April 2018) 
[32] Adrianti, Rina, Siska Komala Sari dan Wahyu Hidayat. 2016. Media Pembelajaran Cara Mudah Belajar Shalat Berbasis Augmented Reality untuk Siswa Kelas Tiga Sekolah Dasar (Studi Kasus SD Ar-Rafi'). Eproceeding of Applied Science Vol.2 No.3. Diambil dari: http://libraryeproceeding.telkomuniversity.ac.id/index.php/appliedscience/article/ view/3523 (16 April 2018)

[33] Hendratman, Hendi. 2014. The Magic of CorelDraw. Bandung: Informatika

[34] Muhdaliha, Benny dan Dewa Ray Dharmayana Batuaya. 2017. Film Animasi 2 Dimensi Cerita Rakyat Bali I Ceker Cipak. Jurnal Bahasa Rupa Vol.1 No.1. Diambil dari: https://jurnal.stikiindonesia.ac.id/index.php/jurnalbahasarupa/article/view/143 (10 April 2018)

[35] Jostonchoniv dan Yudhi Windarto. 2013. Pembuatan Film Animasi 3D Cerita Rakyat "The Legend of Toba Lake”. Jurnal Teknik dan Ilmu Komputer Vol.2 No.6. Diambil dari: http://ejournal.ukrida.ac.id/ojs/index.php/TIK/article/viewFile/791/756 (10 April 2018)

[36] Kusmayadi, Imam Suyitno dan Maryaeni. 2017. Pengembangan Multimedia Cerita Rakyat sebagai Penumbuhan Karakter Siswa. Jurnal Pendidikan: Teori, Penelitian, dan Pengembangan Vol.2 No.7. Diambil dari: http://journal.um.ac.id/index.php/jptpp/article/view/9630 (11 April 2018)

[37] Purwanto, Agus dan Yudi Sutanto. 2017. Pembuatan Media Presentasi Animasi Cerita Rakyat untuk Anak Usia Dini dengan Konsep Pemilihan Alternatif Alur Cerita. Jurnal DASI Vol.18 No.3. Diambil dari: http://ojs.amikom.ac.id/index.php/dasi/article/view/1933 (11 April 2018)

[38] Ibrahim, Norshahila, Wan Fatimah Wan Ahmad dan A'fza Shafie. 2015. Multimedia Mobile Learning Application for Children's Education: The Development of Mfolktales. Asian Social Science Journal Vol.11 No.24. Diambil dari: http://www.ccsenet.org/journal/index.php/ass/article/view/48794 (10 April 2018) 